\title{
Structure of SARS-CoV-2 2'-O-methyltransferase heterodimer with RNA Cap analog and sulfates bound reveals new strategies for structure-based inhibitor design
}

\section{Authors}

Monica Rosas-Lemus, ${ }^{1,2 \dagger}$ George Minasov, ${ }^{1,2 \dagger}$ Ludmilla Shuvalova, ${ }^{1,2 \dagger}$ Nicole Inniss, ${ }^{1,2}$ Olga Kiryukhina, ${ }^{1,2}$ Joseph Brunzelle, ${ }^{3}$ and Karla J. F. Satchell. ${ }^{1,2} *$

\author{
Affiliations \\ ${ }^{1}$ Department of Microbiology-Immunology, Northwestern University, Feinberg School of \\ Medicine, Chicago, IL, USA \\ ${ }^{2}$ Center for Structural Genomics of Infectious Diseases, Northwestern University, Feinberg \\ School of Medicine, Chicago, IL, USA \\ ${ }^{3}$ Northwestern Synchrotron Research Center, Life Sciences Collaborative Access Team, \\ Northwestern University, Argonne, IL 60439, USA. \\ ${ }^{\dagger}$ These authors contributed equally to this work \\ *Correspondence: k-satchell@ northwestern.edu
}

Short title: Structural analysis of SARS-CoV-2 nsp16/nsp10

\begin{abstract}
There are currently no antiviral therapies specific against SARS-CoV-2, the virus responsible for the global pandemic disease COVID-19. To facilitate structure-based drug design, we conducted an X-ray crystallographic study of the nsp16/nsp10 2'-O-methyltransferase complex that methylates Cap-0 viral mRNAs to improve viral protein translation and to avoid host immune detection. Heterodimer structures are determined with the methyl donor $S$-adenosylmethionine (SAM), the reaction product $S$-adenosylhomocysteine (SAH) or the SAH analog sinefungin (SFG). Furthermore, structures of nsp16/nsp10 with the methylated Cap-0 analog (m GppA) and SAM or SAH bound were obtained. Comparative analysis revealed flexible loops in open and closed conformations at the $\mathrm{m}^{7} \mathrm{GpppA}$ binding pocket. Bound sulfates in several structures suggested the location of the phosphates in the ribonucleotide binding groove. Additional nucleotide binding sites were found on the face of the protein opposite the active site. These various sites and the conserved dimer interface could be exploited for development of antiviral inhibitors.
\end{abstract}




\section{Introduction}

On December $31^{\text {st }}, 2019$, the World Health Organization (WHO) was alerted of a pneumonia outbreak with an unknown etiology, originating in the Chinese province of Wuhan, Hubei. The etiological agent was identified as a coronavirus, closely related to the virus responsible for Severe Acute Respiratory Syndrome (SARS). The new SARS coronavirus-2 (SARS-CoV-2) causes the severe respiratory infection, Coronavirus Disease 2019 (COVID-19). Within four months, SARS-CoV-2 rapidly spread, sparking a global pandemic. The COVID-19 pandemic has also forced governments to enact "stay-at-home" orders around the world, seriously damaging the global economy (1). According to the World Health Organization, over 17 million SARSCoV-2 infections have been confirmed, of which more than 685,000 were fatal as of Aug 1, 2020 (www.who.int). These data are similar to Johns Hopkins University tracking system (2).

The coronaviridae family of viruses causes disease in birds and mammals, including bats, camels, pigs, and humans. In lower vertebrates, pathogenic coronaviruses cause acute and severe gastrointestinal infections, fevers and organ failure. Three of the seven human-tropic coronaviruses, hCoV-229E, hCoV-NL63, hCoVB-OC43 cause only asymptomatic or mild infections, including the common cold (3). Four other human coronaviruses are linked to severe infections; including, hCoV-HKU1, a common cause of pneumonia, SARS-CoV with a $10 \%$ mortality rate, Middle East Respiratory Syndrome Virus (MERS-CoV) with a 37\% mortality rate, and SARS-CoV-2 currently with a 5\% mortality rate $(3,4)$. Among these, SARS-CoV-2 stands as the one with higher transmissibility, making its containment very difficult (5). As SARS-CoV-2 continues to spread, the need for effective vaccines and therapeutics increases. Therefore, it is urgent to study SARS-CoV-2 mechanisms of infection and replication in order to find effective targets for drug and vaccine development.

Coronaviruses have a large $(\sim 30 \mathrm{~kb})$ single-stranded, positive RNA genome that is $5^{\prime}$-capped, and contains a 3 '-poly-A tail. The orfla and orflab are directly translated, while the rest of the genome serves as template to generate sub-genomic messenger RNAs (mRNAs) transcribed from the 3 '-end, which are later capped and translated (6-8). The first open reading frame produces the large non-structural polyprotein 1a (pp1a) and a programmed -1 ribosomal frameshift results in translation of the larger non-structural polyprotein 1ab (pplab). These polyproteins are subsequently processed into sixteen non-structural proteins (nsp1-16) that assemble to form the Replication-Transcription Complex (RTC) or function as accessory proteins necessary for viral replication $(8,9)$.

The components of the RTC include enzymes that regulate mRNA and genomic RNA synthesis, proofreading, and mRNA maturation. Two of these enzymes are critical for capping viral mRNAs, a tactic employed by multiple RNA viruses to avoid immune detection (10). In eukaryotic cells, mRNA capping is initiated by an RNA triphosphatase (TPase), which removes the $\gamma$-phosphate from the $5^{\prime}$-end of the nascent mRNA transcript, generating a diphosphate $5^{\prime}$ ppN end. An RNA guanylyltransferase (GTase) subsequently catalyzes the hydrolysis of pyrophosphate (PPi) from a guanidine triphosphate (GTP) molecule forming GMP, followed by the transfer of the $\alpha$-phosphate of guanidine monophosphate (GMP) to the diphosphate $5^{\prime}$-ppN transcript end, forming the cap core structure, methylguanine-triphosphate-ribonucleotide, referred to as GpppN. The GpppN formation is followed by $\mathrm{N}^{7}$-methylation of the capping 
guanylate by a guanine- $\mathrm{N}^{7}$-methyltransferase $\left(\mathrm{N}^{7}-\mathrm{MTase}\right)$ to generate the irreversible Cap- 0 . Further methylation at the ribose $2^{\prime}-O$ position of first nucleotide of the RNA is catalyzed by a ribose $2^{\prime}-O$-methyltransferases $\left(2^{\prime}-O\right.$-MTase) to generate Cap- 1 and sometimes at the second nucleotide to generate Cap-2. Both the $\mathrm{N}^{7}$-MTase and $2^{\prime}$ - $O$-MTase use S-adenosyl-L-methionine (SAM) as the methyl group donor $(4,10)$.

For coronavirus mRNA maturation, the TPase activity is mediated by nsp13, $(6,11-13)$ and a still elusive GTase is used to guanylate the 5'-end of the nascent mRNA. The viral non-structural protein 14 (nsp14) $\mathrm{N}^{7}$-MTase activity then generates the Cap-0 (14). Nsp14 is a bifunctional enzyme with independent $\mathrm{N}^{7}$-MTase and exonuclease domains (15). The association of nsp14 with viral non-structural protein 10 (nsp10) specifically stimulates nsp14 exonuclease activity, but has no effect on the $\mathrm{N}^{7}$-MTase activity (16). The coronavirus mRNAs are further modified to have a Cap-1 by the viral 2'-O-methyltransferase (nsp16). Nsp16 is a 7-methylguaninetriphosphate-adenosine $\left(\mathrm{m}^{7} \mathrm{GpppA}\right)$-specific, SAM-dependent $2^{\prime}$ - $O$-MTase $(17,18)$ that is activated upon binding of nsp10 $(16,19)$. Nsp10 is a stable monomeric protein that can also form dodecamers $(20,21)$, in addition to binding to nsp14 and nsp16 $(16,22)$. Although no specific enzymatic activity has been identified for nsp10, it is known that nsp10 is a zinc binding protein and can bind RNA $(14,20,23)$. It has also been found that nsp10 could interact with human adaptor protein complex 2 (24). However, the main known function of it is the stabilization of the SAM binding pocket in nsp16 and nsp14 (19). The nsp16/nsp10-mediated 2'-O-methylation of coronavirus RNA is essential for preventing recognition by the host to evade immune responses that are triggered by viral mRNAs (17).

Structures of the complex of nsp16 with nsp10 have been determined for SARS-CoV and MERS-CoV $(14,18,25,26)$ and the analysis elucidated the structural basis for substrate binding and the proposed $\mathrm{S}_{\mathrm{N}} 2$-mechanism of methyl transfer. In order to facilitate structure-based inhibitor design, we undertook a comprehensive analysis of the structure of the SARS-CoV-2 nsp16/nsp10 heterodimer. Previously, we reported the structure in complex with the methyl donor SAM in part to make public our methods to benefit the research community (27). We herein update and extend the initial findings with a more comprehensive study. In addition to the prior reported structure with SAM bound (27), we present also the nsp16/nsp10 heterodimer complex with the product of the reaction S-adenosylhomocysteine (SAH) and the SAH analog inhibitor sinefungin (SFG). In addition, we describe the first publicly available SARS-CoV-2 structures of nsp16/nsp10 in complex with the Cap-0 analog $\mathrm{m}^{7} \mathrm{GpppA}$, which facilitates detailed analysis of the changes in the conformation of flexible loops of nsp16 upon substrate binding. Furthermore, we report the only crystal structures with sulfate ions bound to the proposed RNA binding groove as well as several additional nucleotide and sugar binding sites located away from the active site. The nsp 16 protein is one of the most conserved proteins of SARS-CoV-2 and related viruses and thus these high resolutions structures are expected to be useful as models for developing new antiviral therapeutics to treat COVID-19 and other diseases caused by coronaviruses.

\section{Results}

Two crystal form of the SARS-CoV-2 2'-O-MTase 
The SARS-CoV-2 proteins nsp10 and nsp16 are encoded by the polycistronic orflab of the (+) ssRNA (Fig. 1A) and are released from the polyproteins by the nsp5 protease (28). Protein nsp10 is a $14.8 \mathrm{kDa}$ protein released from pp1a and pp1ab, while nsp16 is a $33.3 \mathrm{kDa}$ protein only created after a -1 ribosome shift that produces pplab polyprotein (28) (Fig. 1A). This first structure of the nsp16/nsp10 complex from SARS-CoV-2 was determined at $1.8 \AA$ (PDB code $6 \mathrm{WH} 4,\left(\right.$ (27) Fig. 1B). This crystal belonged to the space group $\mathrm{P} 3{ }_{1} 21$ with two polypeptide chains in the asymmetric unit, with chain A (nsp16) and chain B (nsp10) forming a heterodimer. We refer to this crystal form as the "small unit cell".

A second crystal form of the nsp16/nsp10 complex with SAM bound yielded a structure determined at $1.95 \AA$ (PDB code $6 \mathrm{~W} 75$ ). This crystal form belongs to the $\mathrm{P} 3{ }_{2} 21$ space group and has four chains in the asymmetric unit. The four chains were arranged as a dimer of dimers with a butterfly-like shape (Fig. 1C). The two heterodimers interacted by the C-terminus of nsp16 and as well as the N-terminal of nsp10. We refer to this crystal form as the large unit cell.

To determine which stoichiometry existed in solution, we performed analytical size exclusion chromatography (SEC). In the elution profile, we observed a prominent elution peak at $15 \mathrm{ml}$ that corresponded to a molecular weight (m.w.) of $45 \mathrm{kDa}$, which is close to the estimated m.w. of the heterodimer $(49.8 \mathrm{kDa})$. We also observed a small peak at $\sim 17.5 \mathrm{ml}$, containing mostly nsp10 (Fig. 1D, E). No peak was detected corresponding to $\sim 90 \mathrm{kDa}$ that would be consistent with four chains in a complex in solution, showing that the dimer of dimers is the result of crystal packing and that the heterodimer is the most soluble and stable form of the 2-O-MTase complex.

The overall structure of nsp16/nsp10 in the large unit cell was almost identical to the small unit cell structure, including the bound ligands SAM and $\mathrm{Zn}^{2+}$. In order to corroborate the degree of structural identity, the chains of both crystal forms were aligned using the FATCAT server (29). Alignment of nsp16 from the large unit cell (chains A and C) with the small unit cell (chain A) showed significant similarity with a raw root-mean-square deviation (r.m.s.d.) of $0.37 \AA$ and $0.42 \AA$, respectively. The introduction of a flexibility factor in the alignment showed an optimized r.m.s.d. of $0.38 \AA$ for chain A and $0.77 \AA$ for chain C, demonstrating that the nsp16 structures in these two crystal forms are significantly similar, but that they have flexible regions. One of these flexible regions was a part of the loop formed by the residues Asp6931-Phe6947, which was disordered from the residues Lys6933 to Lys6939 in chain C, a likely explanation for the structural differences. The nsp10 alignment had a raw r.m.s.d. of $0.23 \AA$ for chain $\mathrm{B}$ and 0.34 $\AA$ for chain $\mathrm{D}$ and there were no gaps in the alignment. The optimized r.m.s.d. was $0.28 \AA$ and $0.35 \AA$, respectively, indicating very low differences of these chains. Thus, both crystallographic forms were almost identical with small discrepancies caused by different conformations in the flexible loops of nsp16.

\section{Topology of nsp16 and nsp10 and the heterodimer interface}

For this report, the topology of the nsp16 and nsp10 structures were analyzed in greater detail than previously reported (27). The nsp16 protein consist of pp1ab residues 6799-7096 and additional Ser-Asp-Ala residues at the N-terminus derived from the tobacco etch virus (20) protease cleavage site. The $2^{\prime}-O$-MTase catalytic core was comprised of a Rossmann-like $\beta$-sheet 
fold with the canonical 3-2-1-4-5-7-6 arrangement, in which $\beta 7$ is the only antiparallel strand (Fig. 2A). This $\beta$-sheet was sandwiched by eleven $\alpha$-helices and 20 loops (Fig. 2B).

The nsp10 protein consisted of residues $4272-4392$ of ppla and it is composed of three $\beta$-strands ( $\beta$ '1, $\beta$ ' $2, \beta$ '3), which form a central anti-parallel $\beta$-sheet. At one side of the $\beta$-sheet is the large loop that directly interacts with nsp16 and stabilizes the heterodimer complex. At the other side of this $\beta$-sheet there are six helices and loops that form two zinc fingers (Fig. 2C). In other coronaviruses, these zinc fingers are involved in non-specific binding of RNA (14, 23). The Znbinding site 1 was coordinated by the residues Cys4327, Cys4330, Cys4336 and His4343. The Zn-binding site 2 is coordinated by Cys4370, Cys4373, Cys4381, and Cys4383 (Fig. 2D).

The residues that form the nsp16/nsp10 heterodimer interface can be divided into clusters. The clusters for nsp16 are defined as A (residues 6835-6846), B (6874-6889), C (6900-6908) and D (7042-7046). For nsp10 they are defined as cluster I (4293-4300), II (4322-4337) and III (43464349) $(14,18)$. Almost all of the interface contacts between nsp16 and nsp10 are formed by hydrophobic interactions between nsp10, cluster I (Va14295, Met4297, Leu4298) and cluster A (Pro6835, Ile6838, Met6839, Val6842, Ala6843), cluster B (Val6876, Pro6878, Ala6881) and cluster D (Leu7042, Met7045) of nsp16 (Fig. 2E,). The remaining interactions at the interface are mediated by hydrogen bonds and these hydrophilic interactions consist of five direct contacts between residues Lys4296, Leu4298, Ala4324, Tyr4349, and Gly4347 of nsp10 with Lys6836, Gln6875, Ala6881, and Asp6904 of nsp16, plus eight water-mediated interactions (Fig. 2F).

\section{The binding of SAM and SAH and the pan-MTase inhibitor SFG to the methyl donor binding site}

The nsp16 protein catalyzes the transfer of the SAM methyl group to the Cap-0 structure, generating the reaction products SAH and Cap-1. This reaction can be inhibited by SFG, a 5'-aminoalkyl analog of SAH used as a pan-inhibitor of methyltransferases (Fig. 3A). In order to identify potential structural differences between SAM, SAH, and SFG in the SAM binding cleft, we also determined the structures of nsp16/nsp10 in complex with SAH (PDB code 6WKQ) and SFG (6WJT) at 2.0 and $1.98 \AA$ resolution, respectively. These structures showed that SAM binds to a negatively charged cleft formed by $\alpha \mathrm{A}, \alpha \mathrm{z}, \alpha \mathrm{D}$ the loops L5, L9, L11, in nsp16 (Fig. 3B). The adenosine moiety is stabilized by residues Phe6947, Asp6912, Leu6898, Cys6913 and Met6928. The sugar moiety is stabilized by the residues Gly6871, Asp6897 and by two molecules of water that interact with Asn6899. The methionine moiety interacts with Asp6928, Tyr6845, Asn6841 and Gly6871. Notably, SAH and SFG interact with the same residues as SAM without significant modifications in the site or the overall structure (Fig. 3C).

\section{Binding of SAM and $\mathbf{m}^{7} \mathrm{GpppA}$ to the nsp16 catalytic site}

In addition to the methyl donor SAM, the nsp16 catalytic reaction requires a Cap-0-mRNA with an adenosine in position 1 of the single stranded RNA ( $\left.{ }^{7} \mathrm{GpppA}-\mathrm{RNA}\right)$. The crystal structure of the ternary complex of nsp16/nsp 10 with $\mathrm{m}^{7} \mathrm{GpppA}$ and SAM was previously described for the more distant relative MERS-CoV (26), but not for SARS-CoV, wherein the binding of the mRNA was only modeled (14). Herein, we describe the first publicly available structure of a 
lineage B beta-coronavirus nsp16/10 heterodimer in complex with the analog of the substrate of the methylation reaction, $\mathrm{m}^{7} \mathrm{GpppA}$.

The molecule $\mathrm{m}^{7} \mathrm{GpppA}$ bound to the Cap High Affinity Binding Site (HBS) which is a positively charged surface on nsp16 formed by the loops L1, L8, L9, L10 and L12, $\alpha \mathrm{D}$, and the $\eta 3$ (Fig. 3D). The guanosine ring of $\mathrm{m}^{7} \mathrm{GpppA}$ is stacked with Tyr6828. The phosphate groups are mostly stabilized by side chain atoms of Tyr6828, Tyr6930, Lys6935, Thr6970, Ser6999, and Ser7000, and by the main chain atoms of His6972 and Ser7000 of loops 10 (residues 6970-6975) and 12 (residues 6994-6997) (Fig.3E). The adenosine sugar interacts with side chain atoms of Lys6844, Lys6968 and with Asp6928 through a water molecule. The adenine moiety is stabilized by stacking interaction with side chain of Tyr6930 and it is in close proximity with the SAM binding cleft. These interactions are also found in the structure of MERS-CoV nsp16 in complex with Cap-0 (PDB code 5YNM (26)).

The high quality of the crystal structure of the nsp16/10 complex with $\mathrm{m}^{7} \mathrm{GpppA}$ bound facilitated detailed analysis of the catalytic site. The protein nsp16 contains the highly conserved residues Lys6839, Asp6928, Lys6968, and Glu7001, comprising the canonical catalytic motif (K-D-K-E) conserved among class I MTases $(14,18,30)$. These residues are close to the SAM methyl group that is transferred to the $2^{\prime}-\mathrm{OH}$ on the $\mathrm{m}^{7} \mathrm{GpppA}$. NZ of the Lys6968 is in close interaction with the $2^{\prime}-\mathrm{OH}$ of Cap- 0 and possibly activates this oxygen for the nucleophilic attack of the methyl group in SAM (Fig. 3F). In the structure of nsp16/nsp10 with the $\mathrm{m}^{7} \mathrm{GpppA}$ and SAM bound, we detected the presence of one molecule of water (Fig. 3F) that might participate in the stabilization of intermediate catalytic states $(14,18,31)$. Although the nsp16 MTase reaction was previously characterized as $\mathrm{Mg}^{2+}$-dependent, we did not observed this metal bound and it is likely that $\mathrm{Mg}^{2+}$ is involved only in transitory states of catalysis or stability of the protein as previously suggested for dengue virus $2^{\prime}$ - $O$-MTase (32).

\section{The flexibility of the $\mathrm{m}^{7}$ GpppA site in nsp16}

Several studies of SARS-CoV-1 nsp16 demonstrated the stabilization of the SAM cleft upon nsp10 binding and that $\mathrm{m}^{7} \mathrm{GpppA}-\mathrm{RNA}$ binding causes conformational changes (14). However, no crystal structures supporting these conformational changes have as yet been described. The HBS is surrounded by Loop 1 (residues 6824-6834) and a loop formed by L8- ๆ-3 -L9 (residues 6930-6943). These flexible loops are visible for the first time in our structures and thus we could analyse the diverse conformations of nsp16/nsp10 complexes presented in this work.

First, we analyzed structures of the heterodimer with only SAM bound from the large unit cell form (Fig. 4A, green) with the small unit cell form (blue). There are only minor conformational differences for loop 1, however, the L8- ๆ-3 -L9 loop shows a more "open" conformation in the large unit cell and a more "closed" conformation for the small unit cell structure when only SAM is bound. This analysis corroborated that this specific region is flexible and that these loops likely transit from an "open" to a "closed" state in absence of $\mathrm{m}^{7} \mathrm{GpppA}$.

In order to evaluate the position of loops when $\mathrm{m}^{7} \mathrm{GpppA}$ is bound, we analyzed the structural alignment between the high-resolution heterodimer with SAM bound from the small unit cell (Fig. 4A, blue) and the heterodimer in complex with $\mathrm{m}^{7} \mathrm{GpppA}$ and SAM (orange). This 
alignment has an r.m.s.d. of $0.55 \AA$ and we observed that the presence of $\mathrm{m}^{7} \mathrm{Gppp} A$ induces a stable open conformation of residues 6930-6943, which was found also in the heterodimer in complex with $\mathrm{m}^{7} \mathrm{GpppA}$ and SAH (r.m.s.d.=0.12 $\AA$, not shown in Fig. 4A). The main conformational changes were observed near residues 6936-6939, which were displaced in the open conformation and appeared to mitigate clashes with the guanidine sugar and the $1^{\text {st }}$ phosphate group of the $\mathrm{m}^{7} \mathrm{GpppA}$ and Lys6935 (Fig. 5). These changes indicated that the presence of $\mathrm{m}^{7} \mathrm{GpppA}$ stabilized an open state of the Cap-0 binding site, which could facilitate the release of the product upon methylation, this conformation was also observed in other 2'MTase from SARS-CoV-2 structure (PDB code 6WKS) (33).

Furthermore, the C- $\alpha$ chain of nsp16 from SARS-CoV-2 with Cap-0 and SAM bound (Fig. 4B, orange) was aligned with MERS-CoV nsp16 with SAM (violet) or with cap-0 and SAM bound (cyan) over 293 residues. In the absence of the Cap-0, the MERS-CoV nsp16 residues corresponding to residues 6934-6940 in SARS-CoV-2 are disordered, confirming that this loop is flexible. In contrast, Loop 1 and residues 6930-6943 from MERS-CoV m7pppA-nsp16 complex aligns with the open conformation observed in the SARS-CoV-2 $\mathrm{m}^{7} \mathrm{GpppA}-\mathrm{nsp} 16$ complex. This indicates that both $2^{\prime}-O$-MTases have the same open conformation upon Cap-0 binding.

\section{Sulfates align to the RNA binding groove}

The $2^{\prime}$-O-MTase nsp16/nsp10 possibly binds the RNA tail in the positively charged nucleotide binding groove, also known as the low affinity binding site (LBS). There is, as yet, no structural evidence of the arrangement of this part of the viral RNA in the protein and only prediction models have thus far been published $(14,33,34)$. Sulfates are known to bind to the same positions as phosphates in proteins. Since the first small unit cell structure (PDB code 6W4H) was obtained from crystallization conditions with polyethylene glycol (PEG), which did not allow for soaking with substrates, crystals were screened for suitable conditions for soaking with substrates followed by cryoprotection with $2 \mathrm{M}$ lithium sulfate (see methods). We speculated that these molecules of sulfate could indicate the possible phosphates of the RNA molecule. All of the structures with $\mathrm{m}^{7} \mathrm{GpppA}$ also had molecules of sulfates bound at distinct sites and could be superimposed to analyze the position of sulfates (Fig. 6A-C). Sulfate 1 (S1) was in a position next to the SAM cleft in two alternative conformations, which could indicate the importance of charged molecules nearby the catalytic site (Fig. 6B). Sulfate 2 (S2) seems to mimic the phosphate group between the first and the second nucleotide in the RNA and is followed by a zig-zag line of other sulfates (S2-S5) along the positively charged LBS from nsp16 and the extension groove of nsp10. The compilation of these results suggested that the nucleotide binding groove might accommodate four to five nucleotides from the viral $\mathrm{m}^{7} \mathrm{GpppA}-\mathrm{RNA}$ (Fig. $6 \mathrm{~B})$. Thus far, this is the only experimental and structural evidence that reveals the possible position of the RNA in the nucleotide binding groove.

\section{Identification of three additional $m^{7}$ GpppA binding sites in nspl6}

The present comprehensive study of the interaction of $\mathrm{m}^{7} \mathrm{GpppA}$ with nsp16/nsp10 resulted in the unexpected finding of nucleotides in non-catalytic sites of the structures (Fig. 6A and 6C). Although relatively short soaking times were tested to avoid non-specific binding of $\mathrm{m}^{7} \mathrm{GpppA}$, 
nucleotides were consistently found at three different positions, additional to the active site. Here we describe for the first time three non-catalytic nucleotide binding sites as result of soaking the crystals with $\mathrm{m}^{7} \mathrm{GpppA}$ and SAM or SAH. One of the sites showed binding of the guanine and phosphate moiety from $\mathrm{m}^{7} \mathrm{GpppA}$ (designated MGP, Fig. 6D) and is located on the back surface of the protein (Fig. 6C). This site was found occupied in three different experiments. The guanine moiety interacts with the hydrophobic surface formed by Trp6987 and Leu6855 and the $\mathrm{NH}_{2}$ is stabilized by Ser7074 in a small negatively charged cavity (Fig. 6E). The 2'-OH from the sugar is stabilized by hydrogen bonds between a molecule of water, Asp6811, the first phosphate and the $\mathrm{N} 1$ from the Trp6987. The adenosine moiety of the $\mathrm{m}^{7} \mathrm{GpppA}$ ligand was disordered. In the structure without the cap (PDB code $6 \mathrm{~W} 4 \mathrm{H}$ ), this same site was occupied by $\beta$-Dfructopyranose (BDF) (Fig. 6E) indicating that this site is not nucleotide-specific.

Another binding site (ADE1) was occupied by an adenine (ADE) moiety that likewise is derived from the $\mathrm{m}^{7}$ GpppA (Fig. 6C and 5D). The ADE stacked with Trp6803 (Fig. 6F). The third binding site (ADE2) is also occupied by an adenine ring stacking with Tyr7020 (Fig. 6A and $6 \mathrm{G})$. These non-catalytic nucleotide binding sites might represent interactions that would mimic the interaction between nsp16 and the ribonucleotides of the capped mRNA.

\section{Discussion}

The SARS-CoV-2 pandemic has yielded a world-wide effort to understand the molecular mechanisms involved in virus transmission, virulence, and replication (1). The ultimate goal is to identify viral proteins that are amenable for drug targeting and epitopes suitable for vaccine development. Although, previous studies conducted in SARS-CoV and MERS-CoV paved the way for drug discovery and vaccine development, no approved treatments were fully developed (35). Thus, in order to ensure an accurate approach for drug discovery, we present a comprehensive study of the structure of the SARS-CoV-2 2'-O-MTase complex. In addition to the structures reported here, similar structures of the nsp16/nsp10 complex have subsequently been determined by other groups; including structures with SAM (PDB codes 6W61 (36), 7BQ7 (37), 7C2I, and 7C2J (38), with SFG (PDB code 6YZ1, (34)). Independently, another structure of nsp16/nsp10 in complex with $\mathrm{m}^{7} \mathrm{GpppA}+\mathrm{SAM}$ was deposited (PDB code 6WKS (33)), although this structure was released only at a later date.

Previous studies determined that the 2 - $O$-MTases of SARS-CoV-1 and MERS-CoV, which share $93-99 \%$ and $59-66 \%$ identity to SARS-CoV-2 MTase, respectively, are heterodimers formed by binding of nsp10 to nsp16 $(16,22)$. In addition, their structures have provided some insight into nsp10 dependent activation of nps16 MTase activity and catalysis $(14,18,26)$. As variation at the primary sequence level can impact both local and overall structure, ligand binding and structure-based drug design can also be affected. Thus, high resolution structures of the $2^{\prime}-O$-MTase from SARS-CoV-2 are needed to best inform drug discovery for COVID-19.

This study demonstrated that the binding site for the methyl donor SAM is highly conserved, especially the canonical Gly-X-Gly motif located at the end of the $\beta 1$ and $\alpha A$ and Phe6949 as found in almost all class I MTases $(39,40)$. SAM analogs have been proposed as antimicrobials targeting MTases of fungi and parasites $(41,42)$. Here we determined the structure of nsp16/nsp10 with the pan-MTase inhibitor SFG bound and showed that it has nearly identical 
interactions with amino acids side chains as the natural substrate SAM. The high resolution of the structures with SAM, SAH, and SFG bound could facilitate computational design of the small molecules that bind into the SAM binding cleft that might have a higher specificity for SARS-CoV-2. Further, the conservation of the binding cleft residues across the betacoronaviruses suggests that an inhibitor designed for SARS-CoV-2 could also be a broader spectrum inhibitor, which could target other coronavirus nsp16 proteins.

The Cap-0 binding site offers another position in nsp16 that could be a target for small molecule inhibition. Although the published structure of nsp16/nsp10 from SARS-CoV was elucidated with SAM bound, only a computation model of the interaction of nsp16 with $\mathrm{m}^{7} \mathrm{GpppA}-\mathrm{RNA}$ was previously available (14). In order to study the different arrangements in this structure upon cap binding, crystals were soaked with $\mathrm{m}^{7} \mathrm{GpppA}$ in presence of both SAM and SAH. The resulting structures identified the residues that interact with the Cap-0 and showed that conformational changes in the Cap-0 binding site could occur during catalysis. Of particular concern for the potential development of a more broad-spectrum inhibitor that could target the Cap binding site are two nearby loops that are variable in sequence across the beta-coronaviruses that could have an impact on its function within the cell or catalysis (Fig. 5). Our analysis of overlapped structures of nsp16 from the complex nsp16/nsp10 SARS-CoV-2 with the structure of SARS-CoV with the Cap binding site unoccupied demonstrated that these amino acid differences do not affect the overall structure of the complex, but rather are highly flexible loops that are then stabilized upon binding of the Cap. Stabilization of these loops may be critical to obtain a high affinity small molecule inhibitor directed at this site. The high-resolution structure of SARS-CoV-2 with the cap bound should facilitate design of such a molecule.

A computational model of SARS-CoV 2'-O-MTase in complex with RNA was proposed previously using the structure of vaccinia virus MTase as the model (PDB code 1AV6) (14, 33, 34). This model suggested that the residue $\mathrm{Asp}^{75}$ in SARS CoV (Asp6873 in SARS-CoV-2), confers the selectivity of the Cap binding site for $\mathrm{m}^{7} \mathrm{GpppA}$ over $\mathrm{m}^{7} \mathrm{GpppG}$ due to steric hindrance of the Asp residue with the $\mathrm{NH}_{2}$ at position 2 of the guanidyl (14). This residue is conserved in SARS-CoV-2. However, in all our structures with Cap bound, the position 2 of the adenylate from $\mathrm{m}^{7} \mathrm{GpppA}$ is $7 \AA$ away from the oxygen of the Asp6873, suggesting this residue is unlikely involved in the selectivity of the RNA-capped substrate in SARS-CoV-2. Indeed, recent studies show that $\mathrm{m}^{7}$ GpppG-RNA is $2^{\prime}-O$-methylated by nsp $16 / \mathrm{nsp} 10$ from SARS-CoV-2, but at a lower efficiency that ${ }^{7} \operatorname{GpppA}-\mathrm{RNA}(33,43)$, indicating that this site can accommodate $\mathrm{m}^{7} \mathrm{GpppG}$.

In addition to the ligand binding sites, we explored the positively charged nucleotide groove, also named LBS, which leads from the catalytic core toward nsp10. Several efforts to obtain a short RNA bound into this groove of crystals have thus far been unsuccessful, although several computational models have been recently published and are already available for SARS-CoV (14) and SARS-CoV-2 (14, 33, 34). However, no structural evidence of RNA binding was reported. Thus, in order to obtain experimental evidence of the possible accommodation of the phosphate groups for four to five ribonucleotides of the mRNA that will directly interact with nsp16/nsp10 groove, the crystals were cryoprotected with lithium sulfate. The unique arrangement of sulfate molecules in the LBS provides experimental evidence of the possible accommodation of the phosphate groups for four to five ribonucleotides of the mRNA that will 
directly interact with nsp16/nsp10 groove. We speculate that small charged molecules could be designed to prevent binding of mRNA, which could impair the efficiency of the MTase reaction. The potential advantage of targeting a site away from the SAM or Cap binding sites could avoid cross-inhibition of human MTases and preventing toxicity.

To this end, this study revealed previously unnoted features in the structure that could be advantageous for the design of new therapeutics. First, a possible second nucleotide binding site occupied by a guanine moiety was identified on the back of surface of nsp16 when the crystal was soaked with $\mathrm{m}^{7} \mathrm{GpppA}$. This site is not specific for guanine, since we observed also BDF in the structure when cryoprotected with sucrose in the absence of $\mathrm{m}^{7} \mathrm{GpppA}$. The other sites bound the adenine moiety of $\mathrm{m}^{7} \mathrm{GpppA}$. These sites could be positions for interaction with the mRNA, but also have been postulated as allosteric sites (33). The binding of adenine at these positions via stacking with Tyr7020 or Trp6803 suggesting other bases could also bind at these sites indicating that if they are allosteric sites, the ligand may not be highly specific. Thus, these binding sites need to be further studied in order to determine whether the binding of other molecules might affect the activity of the enzyme, and if these newly defined binding sites could be used as potential new candidates for developing inhibitors.

A final focus for development of inhibitors against nsp16 is to target the interface with its activator nsp10. Derived nsp10-peptides were developed to target SARS-CoV-1 nsp10 that interfered with nsp10 binding to nsp16 resulting in inhibition of its activity (44). In our analysis, we found that the residues that form the interface between nsp16 and nsp10 are $100 \%$ conserved with SARS-CoV-1. Thus, we predict that small molecules that target the nsp16/nsp10 interface as well as specific small peptides could also be highly effective inhibitors that would have broader spectrum activity. An advantage of an inhibitor that binds specifically to nsp10 could even have broader implications and potentially also inhibit the exonuclease activity of the $\mathrm{N}^{7}$ MTase nsp14, which likewise uses nsp10 as its activator $(16,45)$.

One problem for the development of antiviral compounds against SARS-CoV-2 is the potential impact of emerged mutations in its genome. The new emerging mutations on SARS-CoV-2 have recently been mapped on the structures of the proteins (https://coronavirus3d.org) (7). Few mutations have emerged for nsp10 and none impact structure. Interestingly, some emerging mutations have been identified for nsp16, but none of these are predicted to disrupt the structure of nsp16. Further, review of these data showed that no mutations of residues at the interface of nsp16 and nsp10 have as yet been detected in SARS-CoV-2 viral variants isolated from around the globe (7). Thus, it is reasoned that a mutation affecting nsp16 activity could result in early immune detection followed by more rapid clearance of virus. In support of this, recent studies have suggested that stimulation of an interferon response early in SARS-CoV-2 infection could result in less severe disease, particularly in younger individuals (46). In addition, previous reports for Mouse Hepatitis Virus (MHV) showed that mice treated with a 29 amino acid peptide derived from the loops of nsp10 that interact with nsp16 inhibit the MTase activity of nsp16. This peptide also promoted survival of the treated mice from the infection and protection was mediated by the interferon response (44). Altogether, this analysis suggests that immunological studies of the impact of nsp16 inhibition could benefit from identification of an inhibitor that can be employed for study of the virus in vitro or in animals. Such an inhibitor could also be used during early infection to stimulate immunity, reducing the likelihood for development of severe 
disease. The structural work found in this study will help with these next stages in our understanding of MTase modification of mRNA and improved treatments for COVID-19.

\section{Materials and Methods}

\section{Protein purification and analytical SEC}

All methods for cloning, expression and purification of nsp16 and nsp10 were previously detailed (27). In order to confirm that the nsp16/nsp10 complex was formed, we performed analytical Size Exclusion Chromatography (SEC) using a Superdex 200 10/30 column with 10 $\mathrm{mM}$ Tris- $\mathrm{HCl}, \mathrm{pH} 7.5,150 \mathrm{NaCl}, 2 \mathrm{mM} \mathrm{MgCl} 2,1 \mathrm{mM}$ TCEP and 5\% glycerol. The standard calibration curve was obtained using combined low molecular weight (LMW) and high molecular weight (HMW) Gel filtration Calibration kits (GE Healthcare). The resulting peaks from the elution of the protein were fractionated in $0.5 \mathrm{ml}$. Each fraction was collected and $8 \mu \mathrm{l}$ of sample was denatured with Laemmli buffer, then separated using 4-15\% gradient SDS-PAGE (Bio-Rad).

\section{Crystallization, data collection, and structure refinement}

The nsp16/nsp10 complex + SAM was set up as $2 \mu$ crystallization drops $(1 \mu 1$ protein: $1 \mu 1$ reservoir solution) in 96-well plates and equilibrated using commercially available Classics II, PEG's II, $\mathrm{AmSO}_{4}$, Anions and ComPAS Suites (Qiagen). Diffraction quality crystals appeared after 5-10 days in 78 conditions, 118 crystals of various complexes were frozen, and 57 data sets were collected. The crystals were soaked, cryoprotected and flash frozen for data collection as follows.

The small unit cell crystal $(6 \mathrm{~W} 4 \mathrm{H})$ was cryoprotected with $25 \%$ of sucrose in the well solution and the large unit cell crystal (6W75) - with 4M sodium formate (Table 1). In order to obtain complexes with SAH and SFG, crystals were transferred into the $10 \mu 1$ drops with their well solutions supplemented with $5 \mathrm{mM}$ of SAM or SFG, soaked for $3 \mathrm{~h}$, cryoprotected with $4 \mathrm{M}$ sodium formate or $2 \mathrm{M} \mathrm{LiSO}_{4}$ and flash frozen. In the attempt to observe the complexes of nsp16/nsp10 with SAM $+\mathrm{m}^{7} \mathrm{GpppA}$ and $\mathrm{SAH}+\mathrm{m}^{7} \mathrm{GpppA}$ crystals were transferred into $10 \mu \mathrm{l}$ drops containing $5 \mathrm{mM}$ SAM or SAH and $0.5 \mathrm{mM}$ of $\mathrm{m}^{7} \mathrm{GpppA}$ in their respective well solutions, soaked for various amount of time from $3 \mathrm{~min}$ to $6 \mathrm{hrs}$ and flash frozen. $2 \mathrm{M} \mathrm{LiSO}_{4}$ was used as a cryoprotectant cryoprotectant in an attempt to observe the binding of sulfates on the places of phosphates from the RNA in the RNA binding groove. Crystals grown in polyethylene glycol (PEG) conditions were found not suitable for these soaks due to a phase separation of $\mathrm{m}^{7} \mathrm{GpppA}$ in presence of PEG.

\section{Data collection and processing}

Almost 120 crystals were screened, and 57 data sets were collected at the Life SciencesCollaborative Access Team (LS-CAT) beamlines D, G and F at the Advanced Photon Source (APS) at the Argonne National Laboratory. All the data sets reported here were collected at the beamline F. Images were indexed, integrated and scaled using HKL-3000 (47). Seven structures were chosen to be described in this manuscript (Table 2). 


\section{Structure solution and refinement}

The first structure of nsp16/nsp10 from SARS-CoV-2 in complex with SAM with the small unit cell was determined by Molecular Replacement with Phaser (48) from the CCP4 Suite (49) using the crystal structure of the nsp16/nsp10 heterodimer from SARS-CoV as a search model (PDB ID 3R24, (14)). For all other crystal structures, refined structure from this crystal form was used as a search model. The initial solutions went through several rounds of refinement in REFMAC v. 5.8.0258 (50) and manual model corrections using Coot (51). The water molecules were generated using ARP/wARP (52), SAM, SAH or SFG, Zinc ions and ligands were added to the model manually during visual inspection in Coot. Translation-Libration-Screw (TLS) groups were created by the TLSMD server (53) (http://skuldbmsc.washington.edu/ tlsmd/) and TLS corrections were applied during the final stages of refinement. MolProbity (54) (http://molprobity.biochem.duke.edu/) was used for monitoring the quality of the model during refinement and for the final validation of the structure. A total of six structures were deposited to the Protein Data Bank (https://www.rcsb.org/) with the assigned PDB codes 6W75, 6WJT, 6WQK, 6WQ3, 6WVN, and 6WRZ with associated validation reports including electron density maps of all ligands of Interest.

\section{Structural alignment}

The PDB coordinates of SARS-CoV nsp16 and nsp10 were analyzed on the FATCAT (29) and PDBFlex servers (55) to perform structural and sequence alignment. Structural alignments and structure figures were downloaded from the servers and modeled in Pymol open source V 2.1 (56).

Acknowledgments: The authors thank Lukasz Jaroszewski and Adam Godzik for construct design and Grant Wiersum for protein expression. This project has been funded in whole or in part with Federal funds from the Department of Health and Human Services. National Institutes of Health, National Institute of Allergy and Infectious Diseases under Contract No. HHSN272201700060C. This research used resources of the Advanced Photon Source, a U.S. Department of Energy (DOE) Office of Science User Facility operated for the DOE Office of Science by Argonne National Laboratory under Contract No. DE-AC02-06CH11357. Use of the LS-CAT Sector 21 was supported by the Michigan Economic Development Corporation and the Michigan Technology Tri-Corridor (Grant 085P1000817).

Author contributions: M.R.-L. and O.K. purified proteins and formed the complex, L.S. conducted crystallization and soaking experiments G.M. and J.B. collected crystallographic data, determined and analyzed structures. M.R.-L. and N.L.I wrote the draft of the manuscript, which was edited by all authors. K.J.F.S. supervised all aspects of the project.

Competing interests: K.J.F.S. has a significant financial interest in Situ Biosciences, LLC, a contract research organization that conducts antimicrobial testing for industrial products including antiviral testing. This work has no overlap with the interests of the company.

Data and materials availability: All data are publicly available in the RCSB Protein Data Bank (www.rcsb.org). Plasmids have been deposited and are available from www.BEIresources.com. 
Raw x-ray diffraction data for small unit cell and large unit cell crystals are deposited at proteindiffraction.org.

\section{References}

1. Keni R, Alexander A, Nayak PG, Mudgal J, Nandakumar K. COVID-19: Emergence, Spread, Possible Treatments, and Global Burden. Front Public Health. 2020;8:216.

2. Dong E, Du H, Gardner L. An interactive web-based dashboard to track COVID-19 in real time. Lancet Infect Dis. 2020.

3. Ye ZW, Yuan S, Yuen KS, Fung SY, Chan CP, Jin DY. Zoonotic origins of human coronaviruses. Int J Biol Sci. 2020;16(10):1686-97.

4. Chan JF, Kok KH, Zhu Z, Chu H, To KK, Yuan S, et al. Genomic characterization of the 2019 novel human-pathogenic coronavirus isolated from a patient with atypical pneumonia after visiting Wuhan. Emerg Microbes Infect. 2020;9(1):221-36.

5. Petersen E, Koopmans M, Go U, Hamer DH, Petrosillo N, Castelli F, et al. Comparing SARSCoV-2 with SARS-CoV and influenza pandemics. Lancet Infect Dis. 2020.

6. Kim D, Lee JY, Yang JS, Kim JW, Kim VN, Chang H. The Architecture of SARS-CoV-2 Transcriptome. Cell. 2020;181(4):914-21 e10.

7. Sedova M, Jaroszewski L, Alisoltani A, Godzik A. Coronavirus3D: 3D structural visualization of COVID-19 genomic divergence. Bioinformatics. 2020.

8. Sola I, Almazan F, Zuniga S, Enjuanes L. Continuous and Discontinuous RNA Synthesis in Coronaviruses. Annu Rev Virol. 2015;2(1):265-88.

9. Masters PS. The molecular biology of coronaviruses. Adv Virus Res. 2006;66:193-292.

10. Ramanathan A, Robb GB, Chan SH. mRNA capping: biological functions and applications. Nucleic Acids Res. 2016;44(16):7511-26.

11. Furuichi Y, Shatkin AJ. Viral and cellular mRNA capping: past and prospects. Adv Virus Res. 2000;55:135-84.

12. Hussain S, Pan J, Chen Y, Yang Y, Xu J, Peng Y, et al. Identification of novel subgenomic RNAs and noncanonical transcription initiation signals of severe acute respiratory syndrome coronavirus. J Virol. 2005;79(9):5288-95.

13. Ivanov KA, Thiel V, Dobbe JC, van der Meer Y, Snijder EJ, Ziebuhr J. Multiple enzymatic activities associated with severe acute respiratory syndrome coronavirus helicase. J Virol. 2004;78(11):5619-32.

14. Chen Y, Su C, Ke M, Jin X, Xu L, Zhang Z, et al. Biochemical and structural insights into the mechanisms of SARS coronavirus RNA ribose 2'-O-methylation by nsp16/nsp10 protein complex. PLoS Pathog. 2011;7(10):e1002294.

15. Minskaia E, Hertzig T, Gorbalenya AE, Campanacci V, Cambillau C, Canard B, et al. Discovery of an RNA virus 3'->5' exoribonuclease that is critically involved in coronavirus RNA synthesis. Proc Natl Acad Sci U S A. 2006;103(13):5108-13.

16. Bouvet M, Lugari A, Posthuma CC, Zevenhoven JC, Bernard S, Betzi S, et al. Coronavirus Nsp10, a critical co-factor for activation of multiple replicative enzymes. J Biol Chem. 2014;289(37):25783-96.

17. von Grotthuss M, Wyrwicz LS, Rychlewski L. mRNA cap-1 methyltransferase in the SARS genome. Cell. 2003;113(6):701-2. 
18. Decroly E, Debarnot C, Ferron F, Bouvet M, Coutard B, Imbert I, et al. Crystal structure and functional analysis of the SARS-coronavirus RNA cap 2'-O-methyltransferase nsp10/nsp16 complex. PLoS Pathog. 2011;7(5):e1002059.

19. Chen Y, Guo D. Molecular mechanisms of coronavirus RNA capping and methylation. Virol Sin. 2016;31(1):3-11.

20. Joseph JS, Saikatendu KS, Subramanian V, Neuman BW, Brooun A, Griffith M, et al. Crystal structure of nonstructural protein 10 from the severe acute respiratory syndrome coronavirus reveals a novel fold with two zinc-binding motifs. J Virol. 2006;80(16):7894-901.

21. Su D, Lou Z, Sun F, Zhai Y, Yang H, Zhang R, et al. Dodecamer structure of severe acute respiratory syndrome coronavirus nonstructural protein nsp10. J Virol. 2006;80(16):7902-8.

22. Pan J, Peng X, Gao Y, Li Z, Lu X, Chen Y, et al. Genome-wide analysis of protein-protein interactions and involvement of viral proteins in SARS-CoV replication. PLoS One. 2008;3(10):e3299.

23. Matthes N, Mesters JR, Coutard B, Canard B, Snijder EJ, Moll R, et al. The non-structural protein Nsp10 of mouse hepatitis virus binds zinc ions and nucleic acids. FEBS Lett. 2006;580(17):4143-9.

24. Gordon DE, Jang GM, Bouhaddou M, Xu J, Obernier K, White KM, et al. A SARS-CoV-2 protein interaction map reveals targets for drug repurposing. Nature. 2020.

25. Debarnot C, Imbert I, Ferron F, Gluais L, Varlet I, Papageorgiou N, et al. Crystallization and diffraction analysis of the SARS coronavirus nsp10-nsp16 complex. Acta Crystallogr Sect F Struct Biol Cryst Commun. 2011;67(Pt 3):404-8.

26. Wei SM, Yang, L., Ke, Z.H., Liu, Q.Y., Che, Y., Yang, Z.Z., Guo, D.Y., Fan, C.P. Crystal structure of MERS-CoV nsp10/nsp16 complex bound to SAMor bound to SAM and m7GpppA. RCSB Protein Data Bank. DOI: 10.2210/pdb5YNM/pdb; DOI: 10.2210/pdb5YN6/pdb. Release date 12/05/2018.

27. Rosas-Lemus M, Minasov G, Shuvalova L, Inniss NL, Kiryukhina O, Wiersum G, et al. The crystal structure of nsp10-nsp16 heterodimer from SARS-CoV-2 in complex with Sadenosylmethionine. bioRxiv. 2020:2020.04.17.047498.

28. Wu A, Peng Y, Huang B, Ding X, Wang X, Niu P, et al. Genome Composition and Divergence of the Novel Coronavirus (2019-nCoV) Originating in China. Cell Host Microbe. 2020;27(3):325-8.

29. Ye Y, Godzik A. FATCAT: a web server for flexible structure comparison and structure similarity searching. Nucleic Acids Res. 2004;1(32):582-5.

30. Bollati M, Milani M, Mastrangelo E, Ricagno S, Tedeschi G, Nonnis S, et al. Recognition of RNA cap in the Wesselsbron virus NS5 methyltransferase domain: implications for RNA-capping mechanisms in Flavivirus. J Mol Biol. 2009;385(1):140-52.

31. Aouadi W, Blanjoie A, Vasseur JJ, Debart F, Canard B, Decroly E. Binding of the Methyl Donor S-Adenosyl-1-Methionine to Middle East Respiratory Syndrome Coronavirus 2'O-Methyltransferase nsp16 Promotes Recruitment of the Allosteric Activator nsp10. J Virol. 2017;91(5).

32. Zhao Y, Soh TS, Lim SP, Chung KY, Swaminathan K, Vasudevan SG, et al. Molecular basis for specific viral RNA recognition and 2'-O-ribose methylation by the dengue virus nonstructural protein 5 (NS5). Proc Natl Acad Sci U S A. 2015;112(48):14834-9. 
33. Viswanathan T, Arya S, Chan SH, Qi S, Dai N, Misra A, et al. Structural basis of RNA cap modification by SARS-CoV-2. Nat Commun. 2020;11(1):3718.

34. Krafcikova P, Silhan J, Nencka R, Boura E. Structural analysis of the SARS-CoV-2 methyltransferase complex involved in RNA cap creation bound to sinefungin. Nat Commun. 2020;11(1):3717.

35. Martinez MA. Compounds with Therapeutic Potential against Novel Respiratory 2019 Coronavirus. Antimicrob Agents Chemother. 2020;64(5).

36. Kim Y, Jedrzejczak, R., Maltseva, N., Endres, M., Godzik, A., Joachimiak, A., Center for Structural Genomics of Infectious Diseases (CSGID). Crystal Structure of the methyltransferase-stimulatory factor complex of NSP16 and NSP10 from SARS CoV-2. RCSB Protein Data Bank. DOI: 10.2210/pdb6W61/pdb. Release date 3/25/2020.

37. Yan LM, Huang, Y.C., Lou, Z.Y., Rao, Z.H. Crystal structure of 2019-nCoV nsp16-nsp10 complex. RCSB Protein Data Bank. DOI: 10.2210/pdb7BQ7/pdb. Release date 3/24/2020.

38. Lin S, Chen H, Ye F, Chen Z, Yang F, Zheng Y, et al. Crystal structure of SARS-CoV-2 nsp10/nsp16 2'-O-methylase and its implication on antiviral drug design. Signal Transduct Target Ther. 2020;5(1):131.

39. Schubert HL, Blumenthal RM, Cheng X. Many paths to methyltransfer: a chronicle of convergence. Trends Biochem Sci. 2003;28(6):329-35.

40. Smietanski M, Werner M, Purta E, Kaminska KH, Stepinski J, Darzynkiewicz E, et al. Structural analysis of human 2'-O-ribose methyltransferases involved in mRNA cap structure formation. Nat Commun. 2014;5:3004.

41. Nolan LL. Molecular target of the antileishmanial action of sinefungin. Antimicrob Agents Chemother. 1987;31(10):1542-8.

42. Zheng S, Hausmann S, Liu Q, Ghosh A, Schwer B, Lima CD, et al. Mutational analysis of Encephalitozoon cuniculi mRNA cap (guanine-N7) methyltransferase, structure of the enzyme bound to sinefungin, and evidence that cap methyltransferase is the target of sinefungin's antifungal activity. J Biol Chem. 2006;281(47):35904-13.

43. Benoni R, Krafcikova P, Baranowski MR, Kowalska J, Boura E, Cahová H. Substrate specificity of SARS-CoV-2 nsp10-nsp16 methyltransferase. bioRxiv. 2020:2020.07.30.228478.

44. Wang Y, Sun Y, Wu A, Xu S, Pan R, Zeng C, et al. Coronavirus nsp10/nsp16 Methyltransferase Can Be Targeted by nsp10-Derived Peptide In Vitro and In Vivo To Reduce Replication and Pathogenesis. J Virol. 2015;89(16):8416-27.

45. Ferreira de Freitas R, Ivanochko D, Schapira M. Methyltransferase Inhibitors: Competing with, or Exploiting the Bound Cofactor. Molecules. 2019;24(24).

46. Zhou Z, Ren L, Zhang L, Zhong J, Xiao Y, Jia Z, et al. Heightened Innate Immune Responses in the Respiratory Tract of COVID-19 Patients. Cell Host Microbe. 2020;27(6):883-90 e2.

47. Minor W, Cymborowski M, Otwinowski Z, Chruszcz M. HKL-3000: the integration of data reduction and structure solution--from diffraction images to an initial model in minutes. Acta Crystallogr D Biol Crystallogr. 2006;62(Pt 8):859-66.

48. McCoy AJ, Grosse-Kunstleve RW, Adams PD, Winn MD, Storoni LC, Read RJ. Phaser crystallographic software. J Appl Crystallogr. 2007;40(Pt 4):658-74. 
49. Winn MD, Ballard CC, Cowtan KD, Dodson EJ, Emsley P, Evans PR, et al. Overview of the CCP4 suite and current developments. Acta Crystallogr D Biol Crystallogr. 2011;67(Pt 4):235-42.

50. Murshudov GN, Skubak P, Lebedev AA, Pannu NS, Steiner RA, Nicholls RA, et al. REFMAC5 for the refinement of macromolecular crystal structures. Acta Crystallogr D Biol Crystallogr. 2011;67(4):355-67.

51. Emsley P, Cowtan K. Coot: model-building tools for molecular graphics. Acta Crystallogr D Biol Crystallogr. 2004;60(Pt 12 Pt 1):2126-32.

52. Morris RJ, Perrakis A, Lamzin VS. ARP/wARP and automatic interpretation of protein electron density maps. Methods Enzymol. 2003;374:229-44.

53. Painter J, Merritt EA. Optimal description of a protein structure in terms of multiple groups undergoing TLS motion. Acta Crystallogr D Biol Crystallogr. 2006;62(Pt 4):439-50.

54. Chen VB, Arendall WB, 3rd, Headd JJ, Keedy DA, Immormino RM, Kapral GJ, et al. MolProbity: all-atom structure validation for macromolecular crystallography. Acta Crystallogr D Biol Crystallogr. 2010;66(Pt 1):12-21.

55. Hrabe T, Li Z, Sedova M, Rotkiewicz P, Jaroszewski L, Godzik A. PDBFlex: exploring flexibility in protein structures. Nucleic Acids Res. 2016;44(D1):D423-8.

56. DeLano WL. Pymol: An open-source molecular graphics tool. CCP4 Newsletter On Protein Crystallog. 2002(40):82-92. 


\section{Figures}

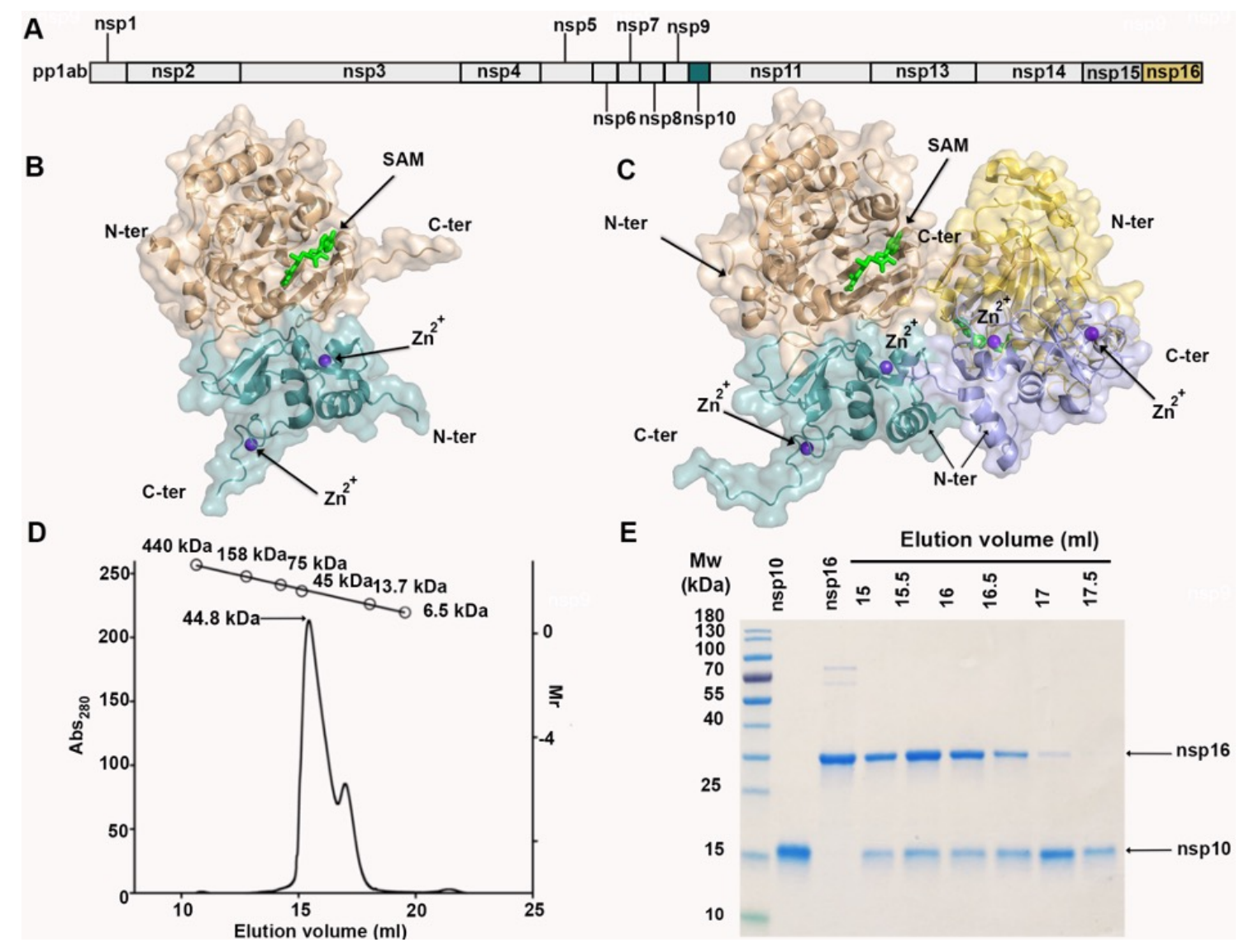

Fig. 1. Overall structure of the nsp16/nsp10 oligomers. (A) Linear schematic of the orfla/orflab protein product pplab prior to proteolytic processing. (B) Cartoon representation of the nsp16/nsp10 heterodimer of the small unit cell crystal form (PDB code 6W4H). (C) Cartoon representation of the two nsp16/nsp10 heterodimers in the asymmetric unit of the large unit cell crystal form (PDB code 6W75). In both panels, nsp16 is shades of tan/yellow and nsp10 is shades of teal/purple. Ligands are represented as sticks with SAM in lime green, and $\mathrm{Zn}^{2+}$ in purple. (D) Elution profile for analytical SEC with relative molecular weight plot of HMW and LMW standards shown at the top. (E) 4-18\% SDS-PAGE gel of the elution fractions stained with Coomassie blue. 


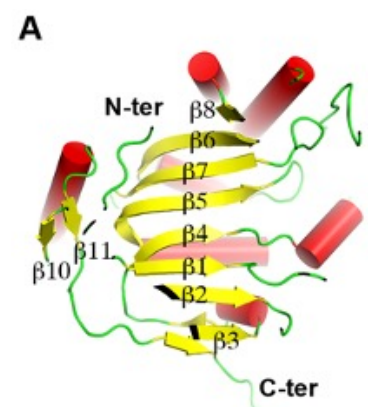

B
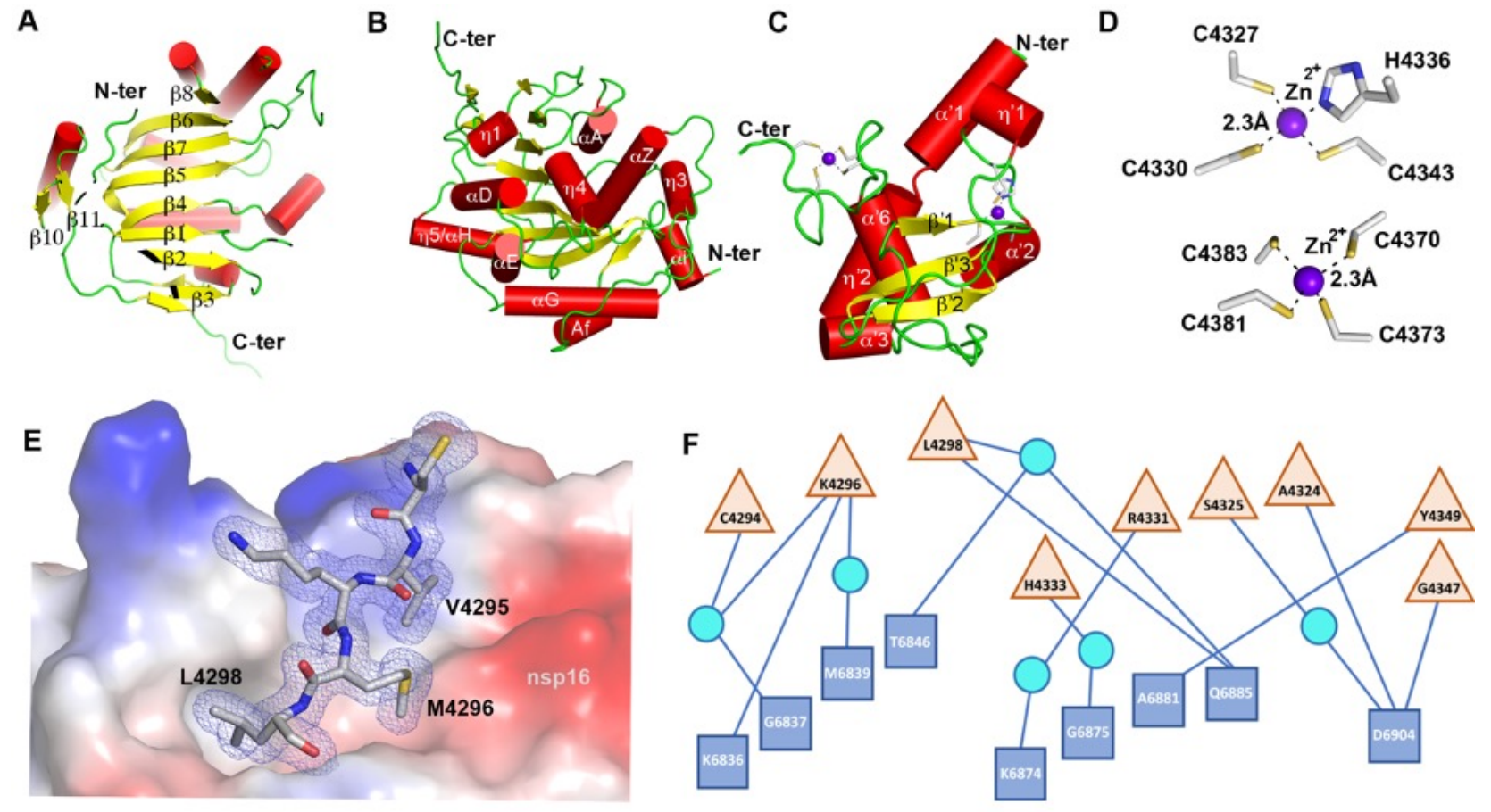

Fig. 2. Detailed representation of nsp16, nsp10, and the heterodimer interface. (A-C) Cartoon representations of two views of nsp16 featuring the canonical $\beta$-sheet from nsp16 (A) and secondary structure of nsp16 (B) and nsp10 (C). For panels A-C, $\alpha$-helices are shown as red cylinders, $\beta$-strands as yellow arrows, loops as lime green strands, and zinc ions as purple spheres. (D) Close-up view of the two $\mathrm{Zn}^{2+}$ binding sites in nsp10. (E) Peptide fragment from nsp10 Cys4294-Leu4298 (sequence CVKML, grey sticks) interaction with the hydrophobic surface of nsp16 (shown as surface charge). (F) Schematic representation of residues from nsp16 (blue squares) and nsp10 (tan triangles) that interact through hydrogen bonds, represented as lines. Some interactions are mediated by water (cyan circles). For panels A-D, structural representations are based on the structure of complex with Cap (PDB code 6WVN). E and F are based on the structure of complex with SAM (PDB code $6 \mathrm{~W} 4 \mathrm{H})$. 


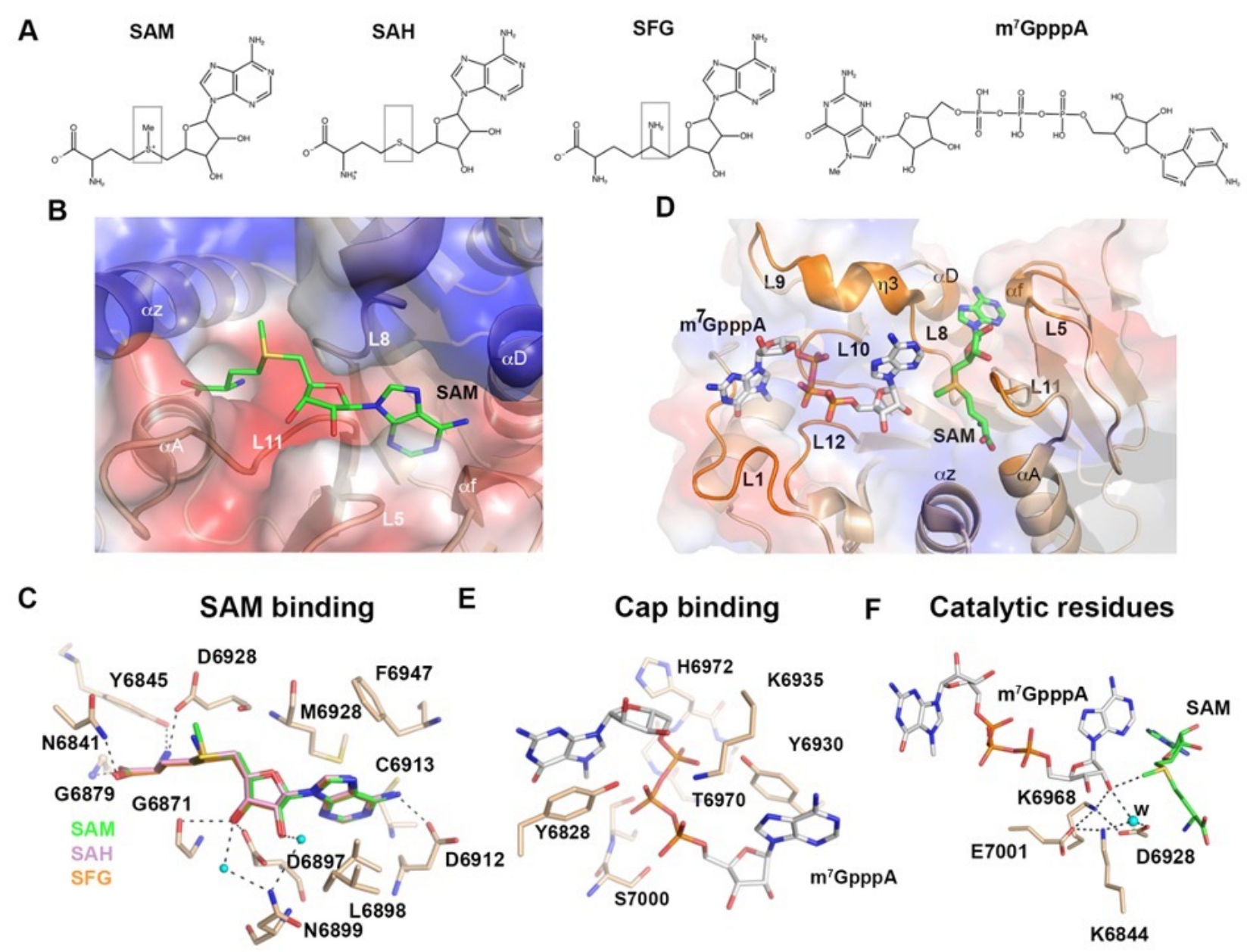

Fig. 3. Ligand interactions and catalytic site. (A) Chemical structures of the methyl donor SAM, the product after methyl transfer SAH, and the SAH analog inhibitor SFG and the Cap-0 $\mathrm{m}^{7}$ GpppA. Boxes highlight differences in the chemical structures compared with SAM. (B) Cartoon and surface charge representations of the nsp16 SAM binding cleft occupied by the SAM (green sticks). (C) Close-up view of overlay of nsp16 structures with the ligands SAM (lime green, PDB code 6W75), SAH (pink PDB code 6WJT) and SFG (PDB code 6WQK). (D) Cartoon and surface charge representations of nsp16 (PDB code 6WVN) of the SAM binding cleft occupied by the ligand SAM (lime green sticks) and the Cap binding site occupied by $\mathrm{m}^{7} \mathrm{GpppA}$ (gray sticks). (E) Detailed view of residues that coordinate $\mathrm{m}^{7} \mathrm{GpppA}$ in the binding site as tan sticks. (F) Close-up view of the side chains of catalytic residues showing orientation of the methyl group in SAM in proximity to the acceptor 2'-OH group in m7GpppA. Dashed lines indicate the interactions between the residues in the active site and small cyan dots indicate water (w). Oxygen as red sticks, nitrogen in blue, phosphate in orange and sulfur in yellow. 

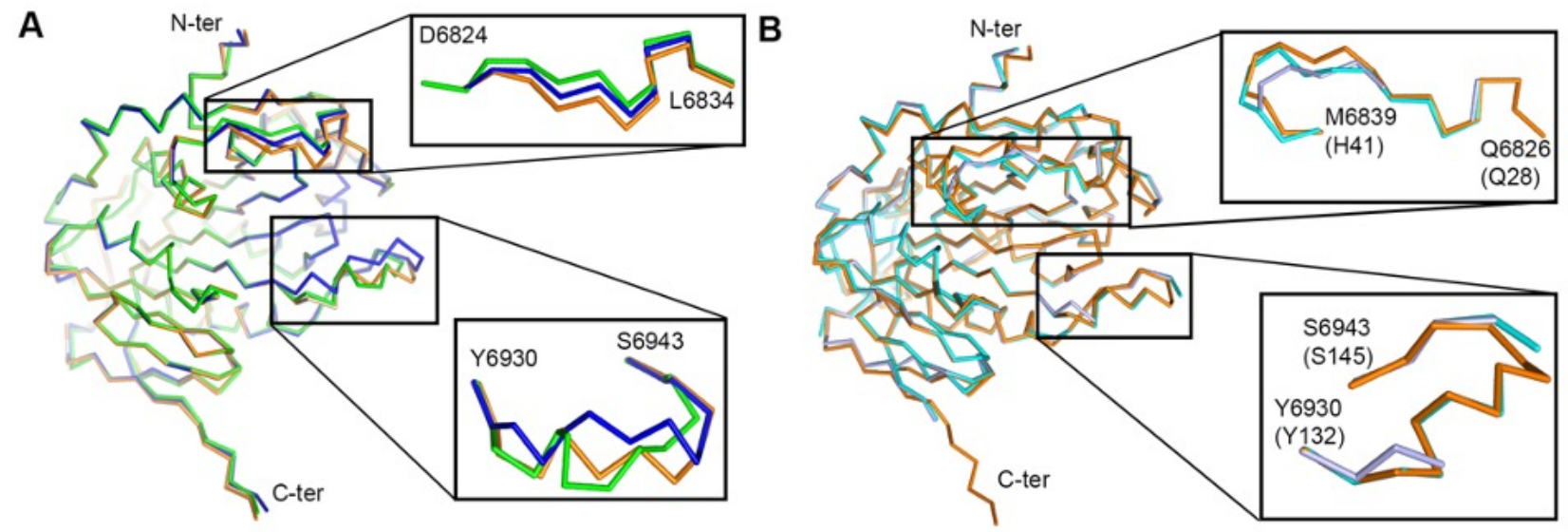

Fig. 4. Structural alignment of nsp16 in presence and absence of $\mathbf{m}^{7} \mathbf{G p p p A}$. (A) Alignment of the C- $\alpha$ chain of nsp16 from SARS-CoV-2 in complex with SAM from the small unit cell (blue, PDB ID 6W4H), nsp16 with SAM from the large unit cell crystal form (green, PDB code 6W75, green) and nsp16 in complex with SAM and $\mathrm{m}^{7} \mathrm{GpppA}$ (orange, PDB code 6WVN). Two flexible loops are enlarged in insets. (B) Alignment of the C- $\alpha$ chain of nsp16 from SARS-CoV2 in complex with SAM and $m^{7}$ GpppA (orange) with MERS-CoV nsp16 with SAM alone (light blue, PDB code 5YN6) or with SAM and $\mathrm{m}^{7}$ GpppA (cyan, PDB code 5YNM), numbering of MERS structure in parenthesis. 


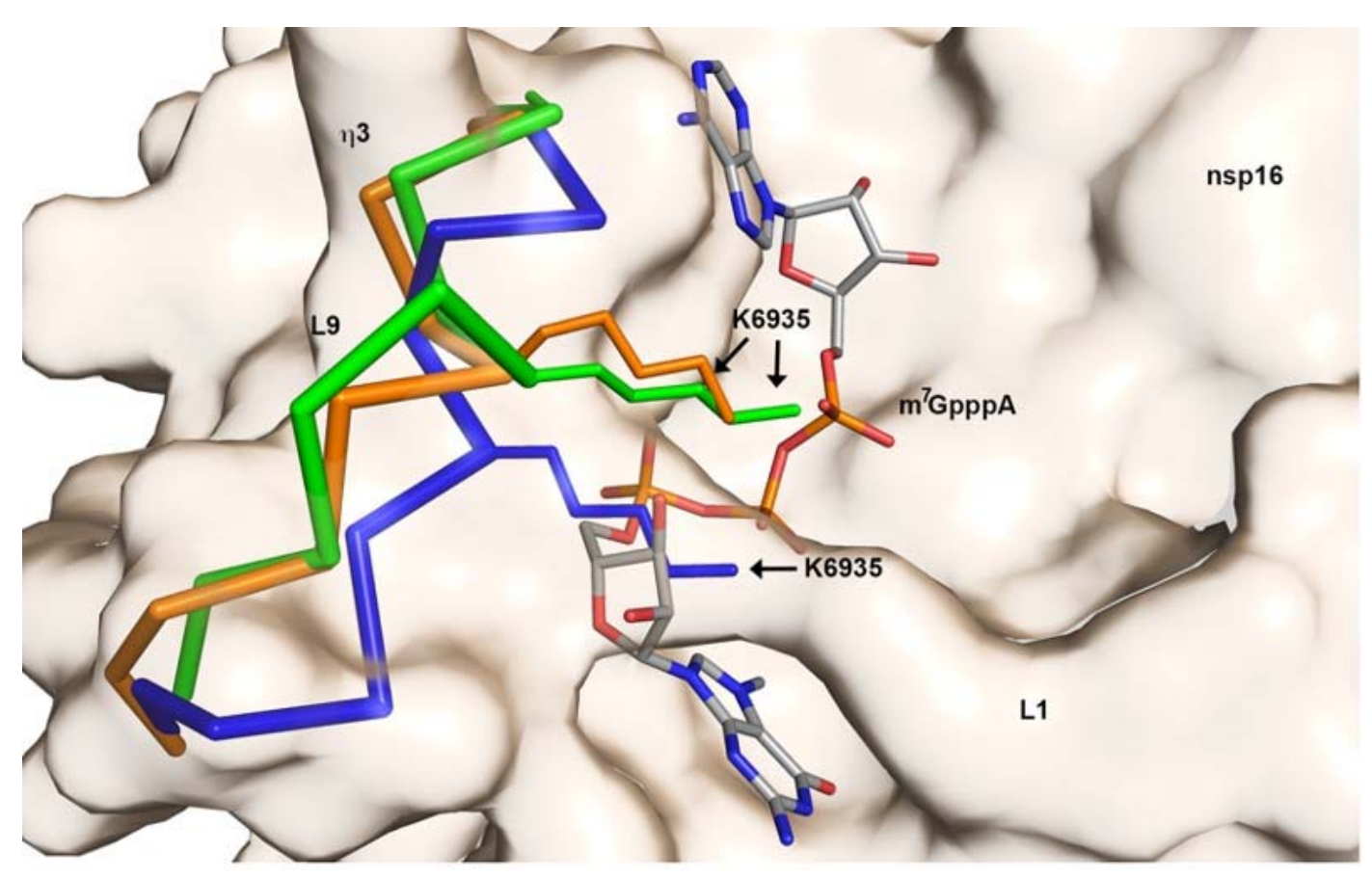

Fig. 5. Displacement of the Lys6935 upon $\mathbf{m}^{7} \mathbf{G p p p A}$ binding. The flexible loops L8-L9 of nsp16, large unit cell with SAM bound PDB code 6W75 (green), small unit cell SAM bound PDB code $6 \mathrm{~W} 4 \mathrm{H}$ (blue) and SAM $+\mathrm{m}^{7} \mathrm{GpppA}, 6 \mathrm{WVN}$ (orange) are shown as C- $\alpha$ ribbon. The Lys6935 as sticks and the $\mathrm{m}^{7} \mathrm{GpppA}$ in gray for carbon; red, oxygen; blue nitrogen and orange phosphate. The surface shown in tan corresponds to the structure PDB code $6 \mathrm{~W} 4 \mathrm{H}$. 

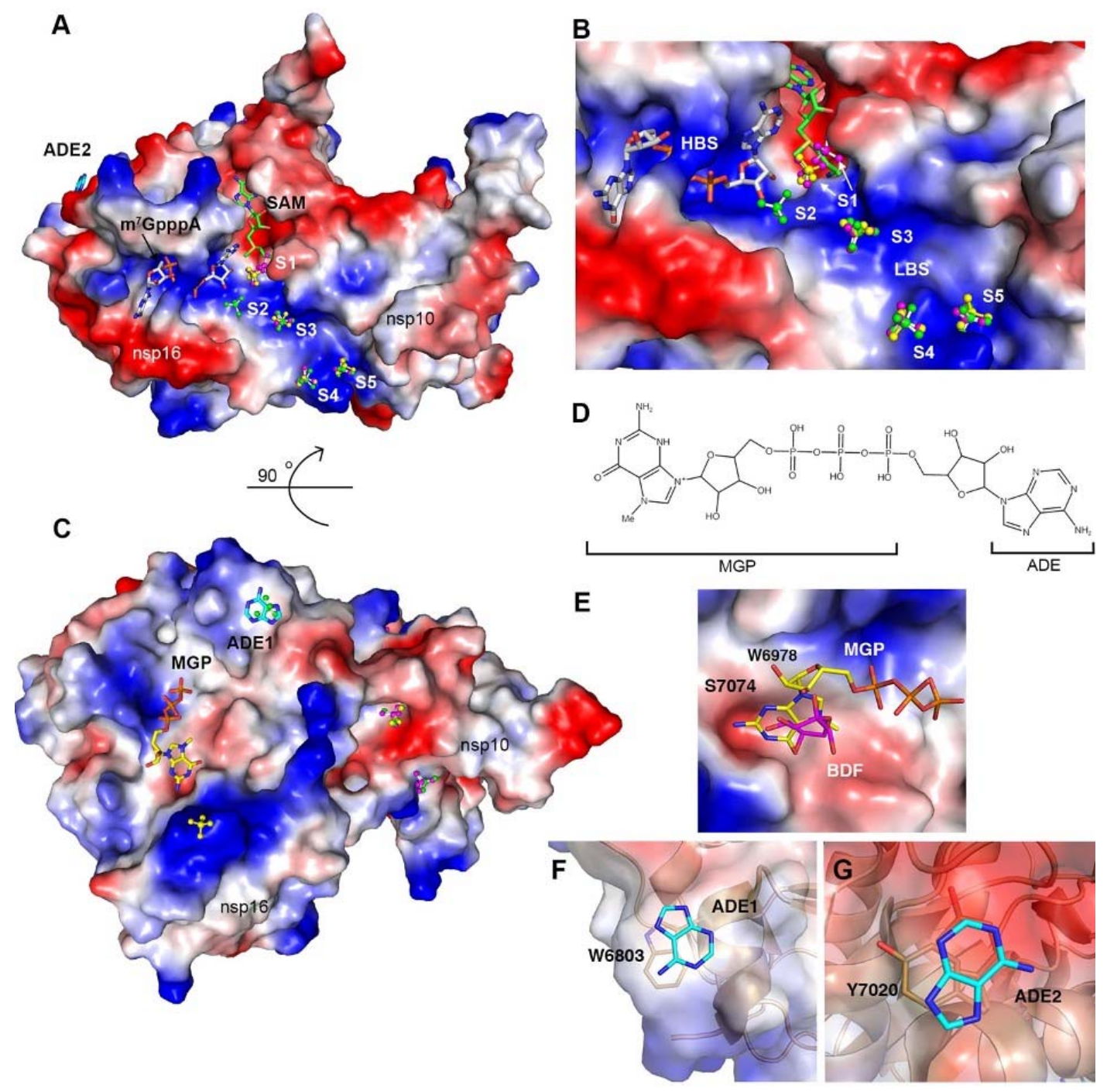

Fig. 6. Sulfates and nucleotides binding sites of nsp16. (A) Surface charge representation, of nsp16/nsp10 with SAM and $\mathrm{m}^{7}$ GpppA bound in green and gray respectively (PDB code 6WVN) and (B) sulfates in balls and sticks along the nucleotide binding groove numbered from the catalytic core to the nsp10 extension (S1-S5). Positive charges in blue and negative charges in red. The sulfates in the overlayed structures are designated by color according with their corresponding PDB code: 6WRZ, 6WVN (yellow), and 6WQ3 (pink). $\mathrm{m}^{7} \mathrm{GpppA}$ is shown as gray sticks and SAM in green sticks. HBS, high affinity binding site; LBS, low Affinity Binding site. (C) $90^{\circ}$ rotation of the complex showing the secondary binding sites MGP and ADE1 along with additional sulfates. (D) Schematic representation of $\mathrm{m}^{7} \mathrm{GpppA}$ and name of the different moieties in the $\mathrm{m}^{7} \mathrm{GpppA}$ structure. (E) Surface charge representation of nsp16 MGP binding site with MGP as (yellow sticks) and BDF from structure 6W4H (pink sticks). (F,G) Cartoon and surface charge representation of the of the adenine moieties (ADE1 and ADE2). For all ligands, carbon as indicated sticks, nitrogen in blue, oxygen in red, phosphates in orange and sulfate in yellow. 
Table 1. Crystallization, soaking and cryoprotection conditions.

\begin{tabular}{|c|c|c|c|c|c|c|}
\hline PDB Accession Code & $6 \mathrm{WVN}$ & 6WQ3 & 6WRZ & 6W75 & 6WKQ & 6WJT \\
\hline $\begin{array}{ll}\begin{array}{l}\text { Protein } \\
(\mathrm{mg} / \mathrm{ml})\end{array} & \text { concentration } \\
\end{array}$ & 5.3 & 5.3 & 5.3 & 9.7 & 5.3 & 5.3 \\
\hline Screen conditions & $\begin{array}{l}0.1 \text { M HEPES } \\
\text { pH } \quad 7.5, \\
0.9 \mathrm{M} \text { Sodium } \\
\text { phosphate, } \\
\text { 0.9M Potassium } \\
\text { phosphate }\end{array}$ & $\begin{array}{l}0.1 \mathrm{M} \text { MES } \mathrm{pH} \\
6.5, \\
0.6 \mathrm{M} \quad \text { tri- } \\
\text { Sodium citrate }\end{array}$ & $\begin{array}{l}0.1 \text { M HEPES } \\
\text { pH } \quad 7.5, \\
0.9 \mathrm{M} \text { Sodium } \\
\text { phosphate, } \\
\text { 0.9M Potassium } \\
\text { phosphate }\end{array}$ & \begin{tabular}{ll}
$0.01 \mathrm{M}$ & Tris \\
$\mathrm{pH}$ & 7.5, \\
$0.4 \mathrm{M}$ & \\
Potassium// \\
\multicolumn{2}{l}{ Sodium tartrate }
\end{tabular} & $\begin{array}{l}0.01 \mathrm{M} \text { Tris, } \\
\mathrm{pH} \quad 7.5, \\
0.4 \mathrm{M} \\
\text { Potassium/ } \\
\text { Sodium tartrate }\end{array}$ & $\begin{array}{l}0.01 \quad \mathrm{M} \\
\text { Tris, } \\
\\
0.02 \quad \mathrm{pH} \\
7.5, \quad 0.4 \mathrm{M} \\
\text { Potassium/ } \\
\text { Sodium } \\
\text { Sartrate }\end{array}$ \\
\hline Soaking solution & $\begin{array}{lr}0.5 \mathrm{mM} & \mathrm{SAM}, \\
0.5 & \mathrm{mM} \\
\mathrm{m}^{7} \mathrm{GpppA} & \end{array}$ & $\begin{array}{lr}0.5 \mathrm{mM} & \text { SAM, } \\
0.5 & \mathrm{mM} \\
\mathrm{m}^{7} \mathrm{GpppA} & \end{array}$ & $\begin{array}{lrr}0.5 \mathrm{mM} & \mathrm{SAH}, \\
0.5 & \mathrm{mM} \\
\mathrm{m}^{7} \mathrm{GpppA} & \end{array}$ & ---- & $0.5 \mathrm{mM} \mathrm{SAH}$ & $0.5 \mathrm{mM}$ SFG \\
\hline Cryoprotectant solution & $\begin{array}{l}\text { 2M Lithium } \\
\text { Sulfate }\end{array}$ & $\begin{array}{l}2 \mathrm{M} \text { Lithium } \\
\text { Sulfate }\end{array}$ & $\begin{array}{l}\text { 2M Lithium } \\
\text { Sulfate }\end{array}$ & $\begin{array}{l}4 \mathrm{M} \text { sodium } \\
\text { formate }\end{array}$ & $\begin{array}{l}4 \mathrm{M} \text { sodium } \\
\text { formate }\end{array}$ & $\begin{array}{l}4 \mathrm{M} \text { sodium } \\
\text { formate }\end{array}$ \\
\hline
\end{tabular}


Table 2. Data collection and crystallography.

\begin{tabular}{|c|c|c|c|c|c|c|}
\hline PDB Accession Code & 6WVN & 6WQ3 & 6WRZ & 6W75 & 6WKQ & 6WJT \\
\hline \multicolumn{7}{|l|}{ Data Collection } \\
\hline Space group & $P 3_{1} 21$ & $P 3_{1} 21$ & $P 3_{1} 21$ & $P 3_{2} 21$ & $P 3_{2} 21$ & $P 3_{2} 21$ \\
\hline \multirow[t]{3}{*}{ Unit cell parameters $\left(\AA{ }^{\circ}{ }^{\circ}\right)$} & $\begin{array}{l}a=b=169.4 \\
c=52.1\end{array}$ & $\begin{array}{l}a=b=169.6 \\
c=52.1\end{array}$ & $\begin{array}{l}a=b=169.14 \\
c=51.8\end{array}$ & $\begin{array}{l}a=b=166.2 \\
c=98.3\end{array}$ & $\begin{array}{l}a=b=166.2 \\
c=98.1\end{array}$ & $\begin{array}{l}a=b=166.9 \\
c=98.1 ;\end{array}$ \\
\hline & $\alpha=\beta=90.0$ & $\alpha=\beta=90.0$ & $\alpha=\beta=90.0$ & $\alpha=\beta=90.0$ & $\alpha=\beta=90.0$ & $\alpha=\beta=90.0$ \\
\hline & $\gamma=120.0$ & $\gamma=120.0$ & $\gamma=120.0$ & $\gamma=120.0$ & $\gamma=120.0$ & $\gamma=120.0$ \\
\hline Resolution range ( $\mathrm{A})$ & $\begin{array}{l}30.00-2.00 \\
(2.03-2.00)\end{array}$ & $\begin{array}{l}30.00-2.10 \\
(2.14-2.10)\end{array}$ & $\begin{array}{l}30.00-2.25 \\
(2.29-2.25)\end{array}$ & $\begin{array}{l}30.00-1.95 \\
(1.98-1.95)\end{array}$ & $\begin{array}{l}30.00-1.98 \\
(2.01-1.98)\end{array}$ & $\begin{array}{l}30.00-2.00 \\
(2.03-2.00)\end{array}$ \\
\hline No. of reflections & $58,029(2,869)$ & $50,035(2,464)$ & $40,141(2,001)$ & $113,483(5,592)$ & $108,598(5,383)$ & $105,884(5,270)$ \\
\hline$R_{\text {merge }}(\%)$ & $7.0(86.7)$ & $7.5(81.1)$ & $7.7(85.7)$ & $7.7(74.2)$ & $7.1(78.4)$ & $10.1(79.5)$ \\
\hline Completeness (\%) & $99.8(100.0)$ & $98.8(98.9)$ & $99.0(99.6)$ & $100.0(100.0)$ & $100.0(100.0)$ & $100.0(100.0)$ \\
\hline$\langle I / \sigma(I)\rangle$ & $20.3(2.1)$ & $21.1(2.3)$ & $23.4(2.8)$ & $25.8(3.2)$ & $22.2(2.0)$ & $16.7(3.2)$ \\
\hline Multiplicity & $5.1(5.1)$ & $7.7(7.8)$ & $7.7(7.3)$ & $7.6(7.6)$ & $5.5(5.2)$ & $6.5(6.6)$ \\
\hline Wilson $B$ factor & 37.4 & 45.4 & 45.1 & 28.4 & 31.7 & 34.2 \\
\hline \multicolumn{7}{|l|}{ Structure Determination } \\
\hline $\begin{array}{l}\text { MR initial model (PDB } \\
\text { ID) }\end{array}$ & $6 \mathrm{~W} 4 \mathrm{H}$ & $6 \mathrm{~W} 4 \mathrm{H}$ & $6 \mathrm{~W} 4 \mathrm{H}$ & $6 \mathrm{~W} 4 \mathrm{H}$ & $6 \mathrm{~W} 75$ & 6W75 \\
\hline \multicolumn{7}{|l|}{ Refinement } \\
\hline Resolution range ( $\mathrm{A})$ & $\begin{array}{l}29.35-2.00 \\
(2.05-2.00)\end{array}$ & $\begin{array}{l}28.31-2.10 \\
(2.15-2.10)\end{array}$ & $\begin{array}{l}29.91-2.25 \\
(2.31-2.25)\end{array}$ & $\begin{array}{l}29.93-1.95 \\
(2.00-1.95)\end{array}$ & $\begin{array}{l}29.92-1.98 \\
(2.03-1.98)\end{array}$ & $\begin{array}{l}29.79-2.00 \\
(2.05-2.00)\end{array}$ \\
\hline Completeness (\%) & $99.8(100.0)$ & $98.8(99.1)$ & $99.0(99.4)$ & $99.9(99.4)$ & $100.0(100.0)$ & $99.8(98.3)$ \\
\hline No. of reflections & $54,988(4,221)$ & $47,173(3,646)$ & $38,166(2,932)$ & $113,455(8,247)$ & $108,429(7,960)$ & $100,620(5,598)$ \\
\hline$R_{\text {work }} / R_{\text {free }},(\%)$ & $\begin{array}{l}16.2 / 17.8 \\
(24.9 / 25.1)\end{array}$ & $\begin{array}{l}16.6 / 18.6 \\
(23.8 / 26.3)\end{array}$ & $\begin{array}{l}16.2 / 19.0 \\
(21.2 / 21.5)\end{array}$ & $\begin{array}{l}15.7 / 17.5 \\
(21.5 / 23.2)\end{array}$ & $\begin{array}{l}16.2 / 18.0 \\
(25.1 / 25.4)\end{array}$ & $\begin{array}{l}17.1 / 19 / 1 \\
(24.5 / 26.9)\end{array}$ \\
\hline Protein chains/atoms & $2 / 3,252$ & $2 / 3,223$ & $2 / 3,214$ & $4 / 6,384$ & $4 / 6,408$ & $4 / 6400$ \\
\hline
\end{tabular}


bioRxiv preprint doi: https://doi.org/10.1101/2020.08.03.234716; this version posted August 14,2020 . The copyright holder for this preprint (which was not certified by peer review) is the author/funder, who has granted bioRxiv a license to display the preprint in perpetuity. It is made available under aCC-BY-ND 4.0 International license.

$\begin{array}{lllllll}\text { Ligand/Solvent atoms } & 197 / 324 & 148 / 245 & 166 / 220 & 125 / 745 & 107 / 636 & 97 / 573 \\ \begin{array}{l}\text { Mean } \\ \left(\AA^{2}\right)\end{array} & 46.9 & 53.8 & 53.5 & 33.9 & 38.1 & 40.7\end{array}$

\begin{tabular}{|c|c|c|c|c|c|c|}
\hline \multicolumn{7}{|c|}{ Coordinate Deviations } \\
\hline R.m.s.d. bonds $(\AA)$ & 0.004 & 0.005 & 0.005 & 0.005 & 0.004 & 0.006 \\
\hline R.m.s.d. angles $\left({ }^{\circ}\right)$ & 1.194 & 1.266 & 1.246 & 1.286 & 1.342 & 1.330 \\
\hline \multicolumn{7}{|l|}{ Ramachandran plot } \\
\hline Favored (\%) & 97.0 & 98.0 & 96.0 & 97.0 & 97.0 & 95.0 \\
\hline Allowed (\%) & 3.0 & 2.0 & 4.0 & 3.0 & 3.0 & 5.0 \\
\hline Outside allowed (\%) & 0.0 & 0.0 & 0.0 & 0.0 & 0.0 & 0.0 \\
\hline
\end{tabular}

